\section{Gesucht: Das beste Titelbild 2015}

Mitmachen und gewinnen! Wählen Sie aus den hier abgebildeten Titelseiten von "DNP - Der Neurologe \& Psychiater" des letzten Jahres die Seite mit dem Bild aus, das Ihnen persönlich am besten gefallen hat. Ihre Mühe wird belohnt. Unter allen Teilnehmern an diesem Gewinnspiel verlosen wir diese attraktiven Preise:

\section{Preis}

Canon Digitalkamera Ixus 275 HS im Wert von $219 €$ (unverbindliche Preisempfehlung)
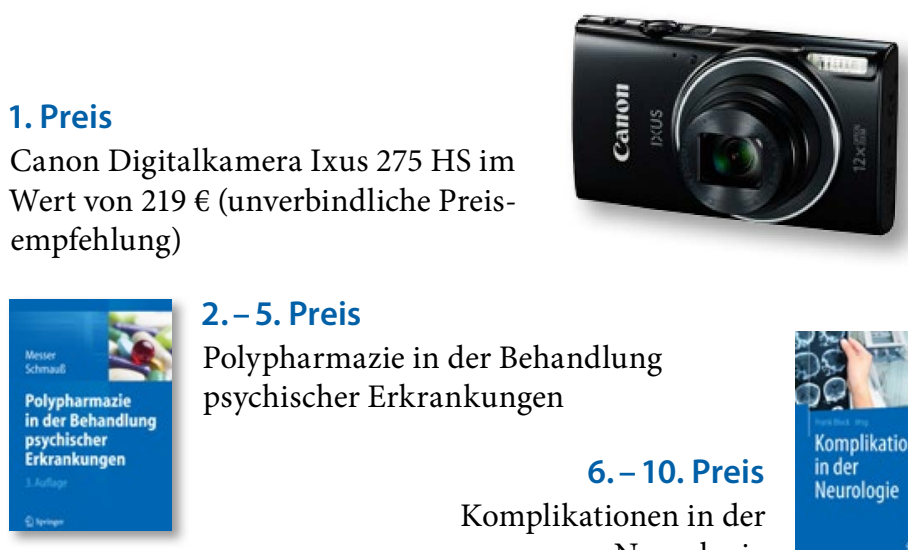

2. -5 . Preis

Polypharmazie in der Behandlung psychischer Erkrankungen

6. -10 . Preis

Komplikationen in der

Neurologie

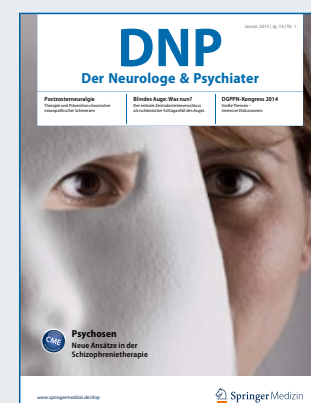

Eine Barauszahlung der Preise ist nicht möglich. Der Rechtsweg ist ausgeschlossen,

Mitarbeiter des Verlages dürfen nicht teilnehmen

DNP-Gewinnspiel „Das beste Titelbild 2015“

\section{Fax $089203043-32404$}

Diese Titelseite gefällt mir am besten: Nummer ...

\begin{tabular}{|l|l|l|l|l|l|l|l|l|l|l|}
\hline 1 & 2 & 3 & 4 & 5 & 6 & $7-8$ & 9 & 10 & 11 & 12 \\
\hline
\end{tabular}

Bitte füllen Sie einfach den Teilnahme-Coupon aus und faxen die Seite bis zum 10. März 2016 an die Redaktion: 0892030 43-32 404. Oder nehmen Sie online unter www.springermedizin.de/gewinnspiel-dnp teil. Dort sehen Sie die Cover auch in größerem Format.

\begin{tabular}{l}
\hline Name, Vorname \\
\hline Straße \\
\hline Postleitzahl $\quad$ Ort
\end{tabular}

庐

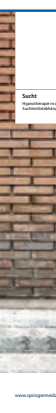

DNP
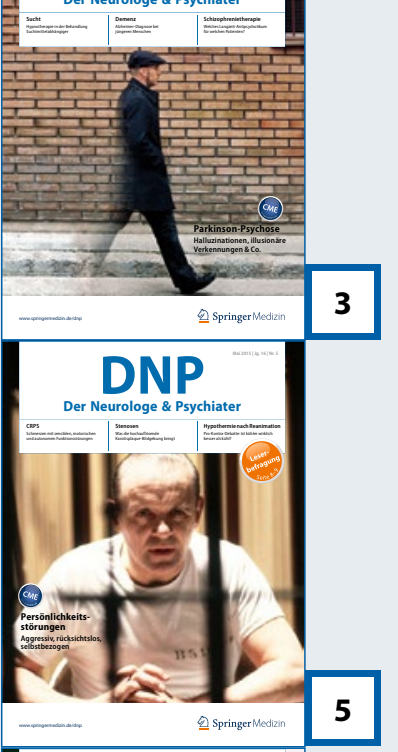

5
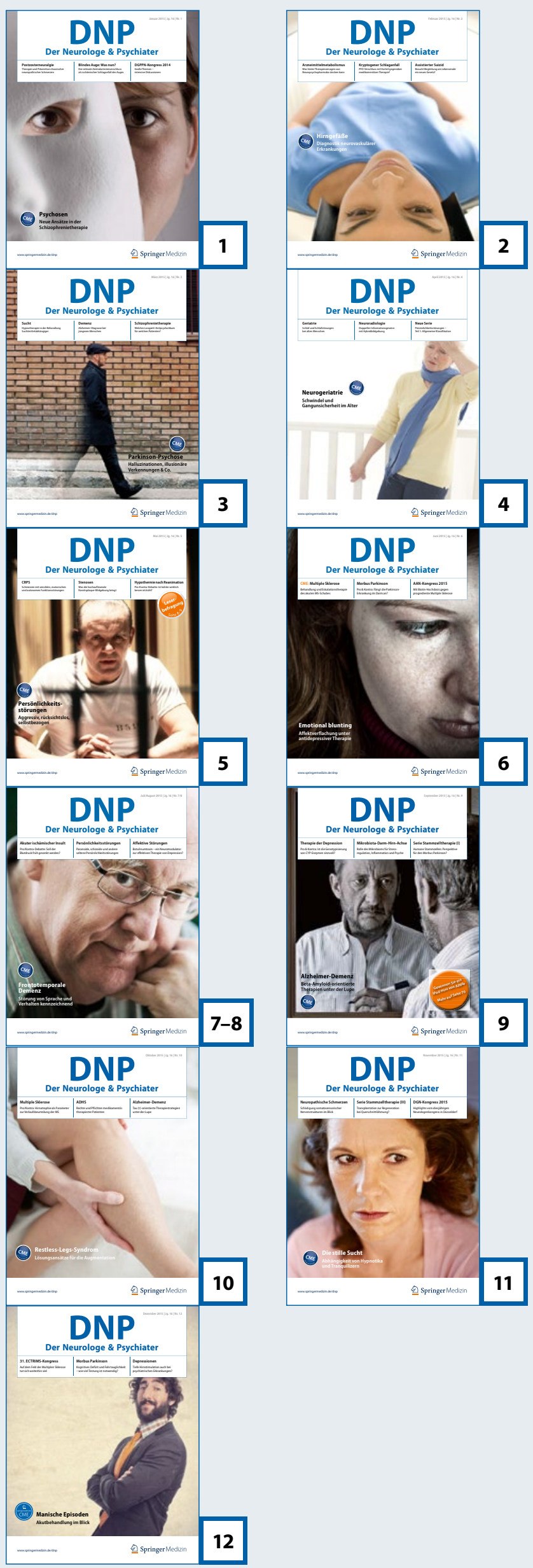